\title{
Prática pedagógica na perspectiva da complexidade: articulaçáo entre educaçáo matemática e educaçáo para a vida
}

Ettiène Guérios ${ }^{1}$

https://orcid.org/0000-0001-5451-9957

\section{Resumo}

O objetivo deste artigo é refletir sobre a prática pedagógica, vinculada a princípios educativos. Tem-se como pressuposto que a docência em matemática, em uma perspectiva de complexidade, pode colaborar para a promoção da autonomia, da cidadania e da justiça social. A abordagem teórica está assentada em dois eixos: educação para a cidadania, como processo educativo para a vida; educação matemática, como educação para a vida. O objeto de reflexão é a prática pedagógica em matemática de uma professora, em sua turma de $7^{\mathrm{a}}$ ano do Ensino Fundamental, em uma escola pública do município de Curitiba. A perspectiva da reflexão está assentada em ideias da complexidade e da transdisciplinaridade. A criatividade é o elemento articulador. Para tal, foram extraídas atividades por ela desenvolvidas e analisadas, sob o ponto de vista da criatividade didática e da perspicácia da docente, da criação ao desenvolvimento em sala de aula. Sob o ponto de vista dos alunos, foram analisadas as repercussóes na aprendizagem matemática e educativa, na compreensão do mundo, em perspectiva planetária. Conclui-se com a defesa de que a aprendizagem conceitual de conteúdos curriculares e a formação educativa constituem um binômio em que uma significa a outra, que por sua vez, são pertinentes para uma escola criativa e transformadora.

Palavras-chave: Complexidade, Transdisciplinaridade, Ação docente, Formação de professores, Matemática e cidadania, Escola e justiça social.

\section{Pedagogical practice from the perspective of complexity: articulation between mathematics education and life education}

\section{Abstract}

The purpose of this paper is to reflect on pedagogical practice, linked to educational principles. It is supposed that teaching mathematics, from the perspective of complexity, may collaborate for the promotion of autonomy, citizenship, and social justice. The theoretical framework is based on two axes: education for citizenship, as an educational process for life; mathematics education, as education for life. The goal of reflection is the pedagogical practice in

\footnotetext{
${ }^{1}$ Professora Titular na Universidade Federal do Paraná. Doutorado em Educaçáo Matemática (UNICAMP). Programa de Pós-Graduaçáo em Educação (Acadêmico) e Programa de Pós-Graduaçáo em Educação: Teoria e Prática de Ensino (Profissional). Membro dos seguintes Grupos de Pesquisa certificados pelo CNPq: a) Cognição, Aprendizagem e Desenvolvimento Humano, b) Ensino e Aprendizagem de Ciências e Matemática e (c) Estudos e Pesquisa Pedagogia, Complexidade e Educaçáo. e-mail ettiene@ufpr.br.
} 
mathematics of a teacher, in her 7th-grade class, in a public school in the city of Curitiba. The perspective of reflection is based on ideas of complexity and transdisciplinarity. Creativity is the articulating element. To accomplish that, activities were extracted from the 7 th-grade teacher, which were developed and analyzed by the teacher herself. The activities are based on the teacher's creativity and perspicacity, and from creation to classroom development. From the student's perspective, the analyzes considered repercussions on the mathematical and educational learning, on the understanding of the world, from a planetary perspective. It concludes with the defense that the conceptual learning of curricular contents and the educational training constitute a binomial in which one signifies the other. Both are pertinent to a creative and transformative school.

Keywords: Complexity, Transdisciplinarity, Teaching action, Teacher Training, Mathematics and Citizenship, School and Social Justice.

\section{Introduçáo}

Este artigo vai ao encontro de um fundamento da Rede Internacional de Escolas Criativas (RIEC) que é da escola criativa e transformadora, em interseção com um dos objetivos da Cátedra UNESCO em Educação para a justiça social (Universidade Autónoma de Madrid) que é aumentar a consciência da importância da Educação para a Justiça Social para a sociedade. Coaduno com os que defendem a Escola como possível caminho para promoção de justiça social. Nesse artigo, reflito sobre a ação docente vinculada a princípios educativos e tenho como pressuposto que a docência em matemática em uma perspectiva de complexidade pode colaborar para a promoção da autonomia, da cidadania e da justiça social. Desenvolvo minha reflexão estimulada por indagaçôes, dentre as quais saliento: como contribuir para uma Formação de Professores [que ensinam matemática] cuja intencionalidade educativa para a prática da cidadania seja motriz de uma docência que coadune aprendizagem conceitual de conteúdos curriculares com formaçáo para a vida? Que tenha a Humanidade planetária como um princípio formativo? Que considere a realidade curricular dos cursos de formação inicial e as práticas da formação continuada de professores em uma perspectiva complexa?

Suanno colabora para a discussão sobre formação de professores em uma perspectiva complexa, com a sistematização que realizou sobre o pensamento complexo e a transdisciplinaridade na educaçáo constantes nos documentos Manifesto de Madrid (2009), Contribuições do II Fórum de Criatividade e Inovação (2010) e Carta de Fortaleza (2010), resultantes de três 
eventos $^{2}$ que se dedicaram a estabelecer diretrizes para subsidiar políticas educacionais, para subsidiar práticas pedagógicas e gerar princípios para a formação de professores e a ação docente por meio de fundamentos ontológicos, epistemológicos e metodológicos do pensamento complexo e da transdisciplinaridade.

Em relação à formação de professores, "os documentos propóem que seja uma formação sólida, transdisciplinar, cidadã, que favoreça o desenvolvimento de uma consciência crítica e de uma consciência ampliada, moral e auto-reflexiva, capaz de perceber outros níveis de realidade". (SUANNO, 2011(b), p.197). Para tal, sugerem que os cursos contemplem ideias constitutivas da complexidade, o que, no meu entender, acarreta outra concepção de formação que transcende a perspectiva dos conhecimentos curriculares - os específicos da docência e os específicos pedagógicos. Pensamento complexo, transdisciplinaridade e ecoformação são indicados como conceitos necessariamente pertencentes aos cursos de formação de professores, se vislumbrarmos tal formação.

Os documentos destacam que "o conhecimento transdisciplinar se constrói por meio de uma tessitura pedagógica complexa, auto-ecoorganizadora, nascida nos interstícios da (inter)subjetividade dos sujeitos envolvidos no processo e em uma pluralidade de percepçóes e significados emergentes". (SUANNO, 2011(b), p.197). Interessante agregar a este destaque a ideia mais objetiva que se tem de complexidade no campo educativo e de profundo alcance interpretativo que é a afirmação de Morin de que complexidade advém de complexus que significa aquilo que é tecido junto (MORIN, CC, p. 215), a que Guérios (2002, p. 161) complementa: "tecer junto os elementos constitutivos da prática pedagógica. Em sua totalidade”. A autora afirma a existência de uma malha constitutiva da prática pedagógica composta por aluno, professor, circunstâncias, conhecimentos específicos, conhecimentos pedagógicos [...] "em que confluem repertório de saberes, repertório de conhecimentos profissionais, em um movimento contínuo e não linear em que as emoçôes, os sentimentos, a imaginação, a intuição, a especulação e a subjetividade são também componentes" (GUÉRIOS, 2002, p. 171).

Os documentos ressaltam a necessária reforma do pensamento proposto por Edgar Morin, pois que "para educar numa sociedade em

\footnotetext{
2 "Manifesto para a criação de um modelo pedagógico Integral” (UNESCO-Madrid, 2009), "Contribuiçóes e conclusóes do II Fórum sobre Inovação e Criatividade" (Barcelona, 2010), e "Carta de Fortaleza/Por uma educação transformadora: os sete saberes da educaçáo para o presente” (UNESCO/Brasil, 2010).
} 
transição, é preciso aprender a pensar em tempos de incerteza e inquietar-se diante das crises de diversas ordens que assolam a sociedade e o planeta" (p.199). De modo interessante e estimulador, "convidam os professores a ousar na criatividade e na inovação, promovendo nas instituições de ensino o desenvolvimento do pensar complexo e transdisciplinar, que busca ecologizar, relacionar, contextualizar e religar diferentes saberes e conhecimentos" (SUANNO, 2011(b), p.199)

Chamou-me atenção a ênfase dada para a criatividade como constitutiva de prática docente transdisciplinar, ênfase essa pertinente tanto pela sua natureza indutora de inovação pedagógica quanto por um aspecto que me é caro, que é o do desenvolvimento humano. Dizem os documentos que em uma perspectiva pedagógica transdisciplinar a criatividade e a inovação "apresentam-se como ferramenta pedagógica fundamental para o desenvolvimento pessoal e coletivo na tomada de consciência dos contextos e conjunturas atuais e na busca de alternativas para o bem comum, no enfrentamento das desigualdades sociais e das mazelas da sociedade contemporânea". (p. 204)

Suanno ressalta a importância que os documentos debitam à obra de Edgar Morin para a formação de professores, em especial "Os sete saberes necessários para a educação do futuro" (Morin, 2000), visto a potência intrínseca que lhes é inerente para a compreensão do universo pedagógico anelado às relaçôes substantivas entre indivíduo, sociedade e natureza. Tal compreensão pode favorecer o entendimento da Escola como possível caminho para promoção de justiça social por meio de uma educação transformadora para o exercício da cidadania, e, portanto, para a vida.

\section{Educaçáo para a cidadania. Processo educativo para a vida.}

Inicio minha reflexão sobre a perspectiva educativa para a vida pelas provocativas palavras de D'Ambrosio, visto que perspectivo um futuro em que justiça, direitos humanos e paz social sejam desafios de uma Educação escolar preocupada com o desenvolvimento de parâmetros para o exercício da cidadania:

[...] nós começamos a perceber que essas duas coisas SOBREVIVÊNCIA E TRANSCEDÊNCIA - estão determinando a busca de explicaçóes para um problema muito maior que é, reconhecer o indivíduo como uma realidade individual . A gente se conhecer. Como uma realidade social. Como uma realidade planetária e 
cósmica. Isso, em busca da harmonia com si próprio, com o outro, com a natureza, com o cosmos. Se nós não estivermos em paz conosco, não há possibilidade de a gente estar em paz com os outros. A busca da paz social depende de nós estarmos em paz com nós mesmos. Ora, se nós não estivermos em paz com a natureza, não estivermos em harmonia com a natureza, nada vai poder acontecer no futuro. Aí não há futuro. (D'AMBROSIO, 1997, p. 30) (grifos da autora).

Há que haver futuro. Entenda-se educação para a cidadania como formação do cidadão ético, solidário, participativo, comprometido, consciente de seus direitos e de seus deveres. Ampliando com Moraes (2019, p.37), o "Conceito de cidadania além de integrar valores de justiça e de identidade, inclui também a complexa mescla de igualdade, liberdade, participação, diálogo, responsabilidade e solidariedade". Estamos falando de um sujeito. De um indivíduo. Um indivíduo humanizado que se compreenda individual, singular e planetário. Morin explica que "A ideia de sujeito origina-se no ser vivo mais arcaico, mas não se reduz a ele. Desenvolve-se com a animalidade, com a afetividade e, no homem, aparece essa novidade extraordinária: o sujeito consciente". (MORIN, 1996, p. 326). Observemos a perspectiva formativa apontada por Guérios e Stoltz no tocante a aprendizagem da cidadania:

Tome-se como princípio que todo homem tem direito á educação para se humanizar, comunicar-se e tomar consciência da sua condição de sujeito transformador da realidade. Nesse sentido não se pode abrir mão da perspectiva crítica reflexiva transformadora na aprendizagem da cidadania; caso contrário, o ser humano entrará em processo de degradação e de barbárie. (GUÉRIOS e STOLTZ, 2015, p. 19).

Uma escola que almeje um futuro com esta perspectiva, certamente, apostará na ousadia pedagógica para o desenvolvimento do pensar complexo e transdisciplinar, como ressaltou Suanno (2011b), o que configura outro conceito de escola. Ou seja, uma escola preocupada náo apenas com o desenvolvimento da intelectualidade dos alunos, cuja prática docente não tem o seu modo de ação didática restrito a transmissão, reprodução e memorização do conhecimento escolar hierarquicamente organizado nos programas escolares. Outrossim, apostará na ousadia refletida em criatividade e inovação. Apostará no desenvolvimento de valores fundamentais para a existência, de sorte que justiça, direitos humanos e paz social sejam compreendidos como necessidade humana. Eis que considerar a perspectiva crítica reflexiva 
transformadora na aprendizagem da cidadania e de seus valores constitutivos significa que, mais do que aprender sobre eles, é preciso vivê-los. Ou seja,

Uma escola que se centra tão somente no desenvolvimento da intelectualidade, desconsiderando o ser integral, não surpreende quando permanece em um discurso vazio acerca dos direitos humanos. É por isso que desponta a necessidade de viver os direitos humanos. Para tanto, é imperioso considerar emoçóes, sentimentos e, sobretudo, a vontade, aliados ao pensar. Falar em educação em a para direitos humanos significa acessar a pessoa na sua inteireza [...] A educação que está posta, não apenas para e em Direitos Humanos, cinde o sujeito do processo de desenvolvimento de sua humanidade por se perder na ideia vazia náo vivida, porque desprovida de significado, por não se voltar a sua realizaçáo concreta transformadora. (GUÉRIOS e STOLTZ, p. $14-15)$

Nesse cenário, criatividade e transformação são imbricadas e ramificam o processo educativo. Pensar em uma escola criativa e transformadora (RIEC) obriga a refletir sobre a ação docente e, consequentemente, sobre a formação de professores. Embora neste artigo eu não discuta especificamente sobre formação de professores, é importante salientar que há vínculo entre esta formação e a ação docente dos professores da Educação Básica, daí a pertinência da observação a seguir.

Montagnini e Suanno (2001 a, p.194) afirmam sobre a necessária valorização da formação pedagógica dos professores universitários, ou seja, dos professores formadores de professores e lembram o quão inócuo é disponibilizar técnicas e metodologias para o ensino, se for de modo estanque, como açáo isolada. As autoras, provocativamente, indagam sobre, que universidade, que didática e que formação de professores universitários são pertinentes em uma realidade complexa. Com propriedade, pontuam que:

A formação de professores universitários não decorre de um processo neutro, mas sim de uma concepçáo de educação, de sociedade, de homem e de trabalho. Destarte, é imprescindível que o docente tenha oportunidade de analisar e refletir acerca de suas concepçóes, com vistas a articular as bases ontológica, epistemológica e metodológica numa perspectiva que se afaste da concepção simplesmente técnica do fazer docente. (MONTAGNINI e SUANNO, 2001a, p.195-196) 


\section{Educaçáo matemática. Educaçáo para a vida.}

As atividades que apresento foram criadas e desenvolvidas por SOUZA (2016) no decorrer de um ano letivo e se constituíram em dados produzidos para sua dissertação de mestrado ${ }^{3}$. Meu objetivo é refletir sobre a ação docente vinculada à princípios educativos e sobre a possível colaboração da docência em matemática em uma perspectiva de complexidade para a promoção da autonomia, da cidadania e da justiça social. Para tanto, reafirmo o pressuposto de que

a docência em matemática pode vincular vertente didática e vertente educativa em um processo único e simultâneo cuja abordagem transcenda a organização disciplinar estabelecida nas matrizes curriculares. Nesse escopo, há uma simbiose entre ambas em que uma fundamenta a outra. Ou seja, ao educar para a vida, ensina-se matemática que, por sua vez, dá sentido à própria existência e possibilita o desenvolvimento de valores como fundamento de uma educação. (GUÉRIOS, 2019, p.226)

Souza é professora de matemática dos Anos Finais do Ensino Fundamental e do Ensino Médio. Para ela, a educação financeira delineia-se como "uma ferramenta no processo de inclusão social e de melhoria de vida do cidadão, incentivando seu planejamento de futuro" (Souza, 2016, p. 89). Preocupada com a aprendizagem matemática de seus alunos, não mede esforços para criar atividades que lhes sejam significativas. Para ela, a matemática é uma via para a compreensão do mundo pelos alunos. Em geral, ela tenta vincular o conteúdo escolar a situaçóes por eles vivenciadas, a preocupaçóes próprias das suas idades e a temáticas emergentes do momento. De modo criativo, Souza estabelece vínculos do presente com o futuro, da vida fora da escola com a vida dentro da escola, do desejo com a perspectiva de realizaçáo, do cotidiano com a aula de matemática. Arrisco a dizer que Souza, assim como os que acreditam que a escola transcende suas estáticas paredes, seguem "em busca de novas inquietaçôes certos de que as melhores respostas poderão ser encontradas onde estão as perguntas mais fecundas” (Ribeiro e Moraes, 2014, p.126).

\footnotetext{
3 Souza (2016) investigou se os conhecimentos de matemática financeira ministrados aos alunos numa perspectiva de Educação Financeira para a vida motivam o aluno da Educação Fundamental para uma aprendizagem significativa dos conteúdos curriculares de modo a promover compreensão conceitual ao mesmo tempo em que os instrumentalizam para a vida. (resumo).
} 
Dito isto, apresentarei atividades que fazem parte de um conjunto delas desenvolvidas durante um período letivo em turmas de $7^{\text {a }}$ série do Ensino Fundamental, em uma escola pública do município de Curitiba. Cada atividade foi desenvolvida em inúmeras aulas, tantas quantas necessárias. Os conteúdos curriculares eram os próprios da matemática financeira curricular. Souza desenvolve atividades de diferentes naturezas. Ela estimula discussóes em sala de aula como rotina pedagógica. Atividade matemática por meio de produção de texto pelos alunos é uma das modalidades que desenvolve. Reflexão educativa por meio de problematização do real é um princípio didático estruturante da atividade matemática, com vistas ao desenvolvimento da autonomia.

A primeira atividade que descrevo trata-se de uma produção de texto em que solicitou que os alunos escrevessem sobre suas lembranças das aulas de matemática que tiveram nos dois anos anteriores: "O que lhe marcou mais, o que fez parte da sua prática em família e o que realmente fez diferença na vida deles e na sua expectativa de futuro" (SOUZA, 2016, p. 65). Eis o enunciado da questão: "Com base nas informaçóes obtidas sobre as questóes de educação financeira e na sua vivência sobre o assunto, produza um texto descrevendo a importância deste aprendizado e o que ele refletiu em sua vida." (IDEM, p. 65).

Souza sistematizou em frases os textos produzidos, das quais apresento algumas a seguir.

- Na sexta série aprendi a lidar com a poupança. Aprendi que abrir uma poupança é melhor que ficar endividado.

- Então é sempre bom planejar o futuro.

- Dei conselhos para a minha mãe, falando para ela fazer uma lista das coisas principais a comprar e se sobrasse algum dinheiro, aí sim compraria outras coisas. Falei também sobre empréstimo, disse que náo vale a pena pois tem muito juros sobre o empréstimo. Essa atividade fez com que as contas diminuíssem um pouco.

- Eu aprendi que tudo precisa de um planejamento, nada funciona se não planejarmos.

- Sem perceber estamos pondo em prática aquilo que aprendemos, pois hoje em dia usamos isso o tempo todo, seja economizando para comprar doces, guardando para sair no fim do mês, tudo envolve coisas que envolvem nosso dia a dia. 
- Me ajudou pois já comecei a pensar no meu futuro e como seria depois de sair da casa dos meus pais. Primeiro comecei a pensar que para me dar bem no mercado de trabalho é preciso estudar muito e me dedicar muito.

- Sabendo o que é débito, crédito, empréstimo, porcentagens podemos controlar melhor a nossa vida. Como vamos entrar no mercado de trabalho sem saber isso, como iremos pedir um empréstimo no futuro sem saber que com o empréstimo vem juros altíssimos, se todos soubessem como fazer um orçamento, poderíamos melhorar muito nossas vidas e gastos.

- Estou procurando um emprego que aceite menor aprendiz.

- Os impostos me ajudaram a perceber quanto dinheiro o governo ganha em cima de nossas compras e gastos, e que muito dessa porcentagem náo volta para o povo em forma de saúde, segurança e educação.

- Tenho muitos planos para a minha vida (viajar para estudar, morar sozinha, etc.) e para realizá-los, eu preciso de dinheiro, e preciso também saber organizá-lo para tudo ficar de acordo com o meu orçamento.

- Hoje eu tenho noção de que se eu deixar a luz do meu quarto acesa a minha conta de luz irá vir mais alta.

- Aprendi que devemos orçamentar as despesas para que não falte no fim do mês e as vezes até sobrar um pouco para comprar mais algumas coisas.

- Se nós adolescentes não começarmos a nos interessar a aprender no futuro, seremos enganados e roubados, depois que eu aprendi na escola sobre isso eu estou mais esperto.

- Mas no futuro não vão ser nossos pais que vão comprar nossa casa, vão pagar a luz, água, etc.

- É importante pensarmos no nosso futuro agora.

- Achei muito interessante o assunto que trabalhamos sobre planejamento familiar, hoje em dia acho isso fundamental até que, hoje em dia na minha casa, existe esse planejamento e sinceramente é bem melhor quando já tem um "orçamento" do que se pode gastar, até sobra dinheiro dependendo do mês. Espero levar todo esse conhecimento pro resto da minha vida e saber administrar corretamente minha família. (SOUZA, 2016, p. 66-70) 
É evidente a sensibilização dos alunos para a aprendizagem. De fato, é perceptível o envolvimento deles com a professora e com o conhecimento matemático. A sutileza de algumas manifestações mostra a relação que os alunos conseguem estabelecer do conteúdo curricular com a vida, com o cotidiano. Lembro que as "lembranças" referem-se às aulas de matemática dos dois anos anteriores, ou seja, náo resultam do que estavam aprendendo no momento da atividade. De modo objetivo, refletiram sobre planos para o futuro, sobre sonhos e expectativas naturais da adolescência, como o trabalho, a vida independente, a construção familiar. Comoveu-me o aluno que afirmou ter colaborado com sua mãe na organizaçáo familiar "dando-lhe conselhos" com o que aprendeu na escola, como também me comoveu aquele que estava procurando emprego como menor aprendiz. Comoveram-me as reflexōes sobre impostos e "retorno" deles para a populaçáo, sobre planejamento para futuro e sobre prospecçóes do presente no futuro.

A reação dos alunos ocorreu de modo espontâneo, não estimulado por palavras ou atitudes vinculadas ao momento da aula, de tal modo que houvesse direcionamento nas respectivas manifestaçóes. Por isso, posso afirmar que houve aprendizagem matemática conceitual. E houve aprendizagem para a vida. De modo criativo, a professora transcendeu obstáculos impostos pela fragmentação do conhecimento matemático escolar em sua própria estrutura, fragmentação desse conhecimento em si, fragmentação do conhecimento com a vida.

Considerando o conjunto de manifestaçóes dos alunos e os conteúdos curriculares a serem ministrados, Souza elaborou a próxima atividade que apresento. Foi uma tabela para a elaboração de um orçamento. Este tipo de atividade - elaboração de tabela orçamentária - é usual na rotina da aula de matemática nos anos finais do Ensino Fundamental. Na tabela constava valor estimado para o total de despesa mensal e receita disponível. Embora a atividade seja usual, o objetivo da organizaçấo da atividade estava expresso no enunciado da atividade e a tornou estimulante: "Para nossa organização de futuro, precisamos prever nossos gastos a fim de determinar nosso próprio orçamento. Complete a tabela com a sua expectativa mensal". Considerando manifestaçôes dos alunos, Souza criou uma série de condicionantes para a elaboração da tabela.

a) Iriam sair de casa a fim de se tornarem independentes financeiros e morar sozinhos;

b) Seriam responsáveis por toda a administração de sua vida, prevendo os gastos e como se 
organizar, criando um planejamento financeiro;

c) Teriam disponível somente o salário disponibilizado ao Menor Aprendiz (nome dado ao projeto de inserção dos adolescentes ao mercado de trabalho): $\mathrm{R} \$ 740,00$ na época;

d) Deveriam pensar em uma estratégia na hipótese de algum imprevisto acontecer;

e) Deveriam, inicialmente, estimar coletivamente, quais as prioridades para subsistência de uma pessoa constando como itens nesse orçamento: água, luz, aluguel, alimentação, etc.

f) Após definição das prioridades, deveriam estimar valores para garanti-las. (SOUZA, 2016, p.69-80).

Em geral, Souza desenvolvia reflexóes matemáticas ao mesmo tempo em que discutia questóes formativas. Os condicionantes são articulados entre si e exigem que os alunos estabeleçam relaçôes entre eles. A atividade exige problematização de situação que, embora hipotética, representava possibilidade real e, por assim ser, provia de significado as relaçóes matemáticas que eles estabeleciam.

Para Souza, era fundamental que os alunos "raciocinassem" e significassem o conteúdo matemático pelo sentido que lhe atribuíssem. Entendia que o que os alunos dissessem sinalizaria a aprendizagem que estariam tendo. Esse era, na verdade, um processo de avaliação que não se manifestava em respostas numéricas próprias de exercícios mecânicos e alheios a realidade dos alunos e, talvez por assim serem, desprovidos de significados. Tanto é verdade, que utilizou como valor financeiro para os cálculos o salário atribuído a quem trabalhava como Menor Aprendiz. Este valor era "real" para eles, visto que um deles havia dito que estava procurando um emprego que aceitasse menor aprendiz. Por isso, perguntou o que os alunos perceberam com a atividade. Eis algumas das percepçóes.

- Concluí que controlar os gastos é muito melhor.

- Eu ia ter que trabalhar mais.

- Se eu seguir um cronograma mensal financeiro posso até fazer meu dinheiro sobrar. 
- O meu salário dá para o mês inteiro, para trabalhar, vou de bicicleta.

- Vou arranjar um segundo emprego.

- Morar com uma amiga temporariamente até achar um emprego melhor.

- Eu pensaria duas vezes antes de sair de casa.

- O dinheiro é muito pouco para muita coisa.

- Sempre é bom melhorar pra ter um salário melhor. (IDEM, p. 72)

Tendo em vista a dinamicidade da vida, o que acarreta mudanças de planos e de rumos, assim como os imprevistos que nos assolam cotidianamente e obrigam mudanças em orçamentos previamente elaborados, perguntou: e se ocorrer imprevistos ou outro objetivo aparecer? Eis algumas manifestaçóes dos alunos.

- Usaria o tempo livre para fazer artesanato e vender pra ganhar o dinheiro que preciso.

- Voltaria para a casa dos pais

- Acharia alguém para dividir o aluguel.

- Separei R\$150,00 para emergência

- Reveria minhas prioridades no mês e programaria o outro. Faria algum "bico" para náo passar muito apuro no mês seguinte.

- Usaria o dinheiro da economia.

- Reveria minhas prioridades e guardaria dinheiro.

- Ficaria no negativo do banco.

- Eu emprestaria do banco, mesmo que tivesse que pagar juros.

- Iria pedir ajuda aos meus pais. (SOUZA, 2016, p. 72-73)

Para Souza era importante a discussão, o diálogo, a reflexão, o exaurir da discussão. Ela criava novas situaçóes, decorrentes uma das outras, para que elos fossem construídos. O que apontei está contemplado na descriçáo de Suanno sobre ambientes de aprendizagem criativos, saudáveis e inovadores. E também, na recomendação de que "professores e estudantes devam estabelecer uma relaçáo humana e profissional de apoio, de confiança, com afetividade, para que assim possam se auto-eco-organizar, construir novas percepçóes 
sobre a realidade, novas atitudes e consciência diante da vida, e construir conhecimentos”. (SUANNO, 2011, p. 201)

A próxima questão problematizava a anterior e estava assim enunciada:

$\mathrm{Na}$ atividade passada pudemos organizar e prever nosso próprio orçamento para o futuro. Pesquisamos preços, realizamos várias reflexôes e agora vamos pensar melhor na última questão: o que faríamos se algum imprevisto tal como: perda do emprego, doença na família, bebê a caminho, acidente, ou algum outro nos forçasse a criar uma nova alternativa? Qual seria a sua opção? Marque a resposta justificando os prós e os contras de sua escolha.

( ) Empréstimo bancário

( ) Trabalho alternativo

( ) Cartão de crédito

( ) Outra solução (p. 74)

A atividade exige conhecimento matemático para fazer a opção, pois o cerne da questão está na justificativa para a opção e não na opção propriamente dita. Não há opção certa ou errada e isto engrandece a atividade. E mais, ao solicitar que justifiquem os "prós e os contras" da escolha, exige que os alunos articulem conhecimentos matemáticos e desenvolvam o raciocínio muito proximamente de como se deve agir na vida. Desta atividade, com o objetivo de colaborar para o desenvolvimento do senso crítico, fez parte uma roda de conversa sobre "escolhas que as pessoas fazem na vida, partindo da hipótese de que o que é qualidade de vida para alguns pode não ser para outros e que a felicidade não está vinculada apenas aos que obtém sucesso financeiro." (SOUZA, 2016, p. 75).

Esta preocupação de Souza levou-me a estabelecer uma aproximação com o dizer de Morin acerca da ideia de progresso vinculada a equívoca concepção de qualidade de vida como capacidade de acumulação. Eis o que nos diz:

[...] o progresso é noção aparentemente evidente; sendo por natureza cumulativa e linear, traduz-se de forma simultaneamente quantitativa (crescimento) e qualitativa (isto é, por um "melhor"). Vivemos durante dezenas de anos com a evidência de que o crescimento econômico, por exemplo, traz ao desenvolvimento social e humano aumento da qualidade de vida e de que tudo isso constitui o progresso. Mas começamos a perceber que pode haver dissociação entre quantidade de bens, de produtos, por [96 ] exemplo, e qualidade de vida; vemos, igualmente, que, a partir de certo limiar, o crescimento pode produzir 
mais prejuízos do que bem-estar e que os subprodutos tendem a tornarse os produtos principais. Portanto, a palavra progresso não é tão clara quanto parece. (MORIN, 1996, p. 95-96).

Entre esta atividade e a próxima, uma série de outras ocorreram, de diferentes naturezas. Tabelas, exercícios, resolução de problemas, escritas. Reflexôes sobre perguntas provocativas são uma constante. Exemplos: o que é ter sucesso financeiro? O que é qualidade de vida? O que é cidadania? O que é prioridade? Quais suas prioridades hoje? O que você pretende no seu futuro? $\mathrm{O}$ que é necessidade? Que estratégias você desenvolverá para resolver determinada situação? O que deixa você feliz?

A próxima atividade teve o objetivo de sistematizar os conhecimentos matemáticos desenvolvidos no decorrer do ano por meio de uma prospecção de futuro e estava assim enunciada:

Após a roda de conversa, pudemos refletir sobre as escolhas que faremos para nosso futuro e o que consideramos ser qualidade de vida. Com base em sua opiniáo sobre o assunto, imagine-se com as idades citadas abaixo, escreva como você planeja chegar a cada uma delas e o que você espera alcançar:

Eu quando tiver 20 anos

Eu quando tiver 40 anos

Eu quando tiver 50 anos

Eu quando tiver 60 anos

Eu quando tiver 70 anos

De modo muito interessante, os alunos deixaram a imaginação fluir e escreveram seus "planejamentos" envolvendo o aspecto financeiro e suas expectativas. Obviamente, jovens alunos de $7^{\circ}$ ano do Ensino Fundamental tem uma visão longínqua no tempo conforme suas idades permitem e conforme os membros familiares que conhecem com que convivem. $\mathrm{O}$ foco estava na sensibilização que a atividade provocaria para a manifestação conceitual dos conhecimentos matemáticos desenvolvidos, nas estratégias que criariam para o tempo em que "se" imaginassem, na manifestação da perspectiva educativa, todas elas articuladas. Aproprio-me de palavras de Souza (2016) sobre a ação docente vinculada a princípios educativos:

Defendemos uma educação financeira não somente informativa baseada em conhecimentos técnicos da Matemática Financeira, transmitidos de forma objetiva, mas sim formativa, que extrapole os conhecimentos técnicos e que modifique atitudes e comportamentos, 
que auxilie na formação de um cidadáo ético e consciente das questôes sociais e ambientais que o tema envolve, numa perspectiva de educaçáo para vida. (idem, p. 104)

Conforme afirmei, coaduno com os que defendem a Escola como possível caminho para promoção de justiça social e afirmo que aprender sobre educação financeira na escola é também aprender sobre valores. É possibilitar que os alunos compreendam a própria vida e construam bases para a compreensão de uma cidadania planetária. Trago de Moraes (2019, p. 37) que "O conceito de cidadania planetária surge a partir de uma consciência que reconhece que todos habitam um planeta que precisa ser cuidado, respeitado, reconhecido, valorizado e amado". Por certo que, intrinsecamente, a intencionalidade de Souza em contribuir com a docência em matemática para a formação de um cidadão ético e consciente das questóes sociais e ambientais encontra ressonância na percepção de Moraes (2019, p. 37), de que “o ser humano é apenas um elo desta corrente comunitária vital, um simples membro de uma imensa comunidade de vida e de destino".

Sem crítica a algum modo didático de desenvolvimento do conteúdo em salas de aula, provoco a reflexão que segue. Suponhamos uma série de enunciados para a aprendizagem do conteúdo curricular "Juros Simples e Compostos" similares à: "Pedro fez um empréstimo de $\mathrm{R} \$ 25.000,00$ para pagar em cinco anos com taxa de juros simples de 10\% ao mês. Qual o montante a ser pago ao final do empréstimo?” Reflitamos. Existe possibilidade dos alunos resolverem corretamente por meio de aplicação de fórmula, sem que haja compreensão, sequer, do que seja juro? A resposta é: sim existe. Qual o vínculo dos alunos com a situação configurada? O que o enunciado lhes diz? Qual o significado atribuído aos dados do enunciado? Não afirmo que problemas alheios a realidade dos alunos não possam ser realizados. Mas, afirmo que problemas deste modo, e apenas desses, poderão resultar em aprendizagem procedimental, mas certamente, não haverá aprendizagem conceitual, tampouco colaborarão para a construção de um conceito de cidadania que o faça perceber-se como um elo de uma comunidade vital de uma comunidade de vida e de destino, como disse Moraes. O "sujeito consciente", que nos diz Morin. 


\section{Consideraçóes}

O objetivo deste artigo foi refletir sobre a prática pedagógica vinculada a princípios educativos, partindo do pressuposto que a docência em matemática, em uma perspectiva de complexidade, pode colaborar para a promoção da autonomia, da cidadania e da justiça social.

A reflexão sobre a prática pedagógica desenvolvida por Souza, docente de matemática no Ensino Fundamental e no Ensino Médio, oferece pistas para uma Formação de Professores complexa, cuja intencionalidade educativa para a prática da cidadania seja motriz de uma docência que coadune aprendizagem conceitual de conteúdos curriculares com formação para a vida e que tenha a humanidade planetária como um princípio formativo.

Criatividade, flexibilidade, aceitação do imprevisível e abertura para o inesperado são algumas dessas pistas. Por meio delas, a perspicácia da docente em problematizar fatos e situaçóes da vida que emergiam no movimento articulado e contínuo entre docente, seus alunos e conteúdos escolares, viabilizou a atribuição de sentido aos conteúdos matemáticos. A reflexão matemática permanente e contínua sobre o fazer matemático, e sobre o feito matemático, possibilitou o desenvolvimento de pensamento estratégico em que conjecturar, elaborar hipóteses, propor soluçóes e refletir sobre elas ocorrem de modo imbricado, sem fronteiras pré determinadas entre um movimento cognitivo e outro.

A perspectiva da reflexão esteve assentada em ideias da complexidade e da trasndisciplinaridade, sendo a criatividade o elemento articulador entre o fazer e o pensar. A reflexão sobre a prática pedagógica em tela evidencia o quanto a escola pode ser espaço para a promoçấo da autonomia, da cidadania e da justiça social.

Se analisarmos uma a uma as manifestaçóes dos alunos nas atividades aqui analisadas, perceberemos o desenvolvimento de um pensamento ampliado, que articula o conhecimento matemático com dia a dia, com anseios e devaneios de adolescentes que tem mundo próprio e que foi compreendido e acatado e pela professora como deflagradores de situaçóes para aprendizagem matemática. Com criatividade, previu roteiros para sua docência e transformou em atividade didática o que emergia dos alunos.

Em relação à formação de professores, acredito que o exposto colabora para a formação "sólida, transdisciplinar e cidadã que favoreça o desenvolvimento de uma consciência crítica e de uma consciência ampliada, moral e auto-reflexiva, capaz de perceber outros níveis de realidade" apontada 
nos documentos anteriormente citados, conforme Suanno (2011(b), p.197) chama atenção.

Concluo com a defesa de que a aprendizagem conceitual de conteúdos curriculares e a formação educativa constituem um binômio em que uma significa a outra, que por sua vez, são pertinentes para uma escola criativa e transformadora, que tenha a Humanidade planetária como um princípio formativo e justiça social como meta. Ratifico a percepção manifestada em Guérios e Batistella (2020, p. 666) de que "Aprendizagem conceitual de conteúdos curriculares e formação cidadã constituem um binômio indiscutivelmente agregado". Este binômio é pertinente em uma escola criativa e transformadora, conforme postulado pela RIEC e que tenha como objeto a conscientização acerca da importância da Educação para a justiça social, postulada pela Cátedra UNESCO, Universidade Autónoma de Madrid. Concluo com a certeza de que a prática pedagógica na perspectiva da complexidade possibilita a articulação entre educação matemática e educação para a vida.

\section{Referências}

D'AMBROSIO, U. A era da consciência: aula magna do primeiro curso de pós-graduação em Ciências e Valores Humanos no Brasil. São Paulo: Peirópolis, 1997.

GUÉRIOS, E.; STOLTZ, T. Educação em e para direitos humanos: embates entre a igualdade e a diferença. In: GUÉRIOS, E.; STOLTZ, T (Org) Educaçâo em Direitos Humanos. Qual o sentido? Curitiba, PR: Juruá. 2015. p. 13-28.

GUÉRIOS, E.; BATISTELLA, M. P. Programa, estratégia, movimento, criatividade: eixos na ação didática em uma perspectiva de complexidade. Debates em Educação. Maceió, AL, v. 12, n. 28, p. 665-676, 2020. Disponível em: https://www.seer.ufal.br/index.php/debateseducacao/article/view/9952. Acesso em: 25/08/2020.

GUÉRIOS, E. Espaços oficiais e intersticiais da formação docente: histórias de um grupo de professores na área de ciências e matemática. Tese (Doutorado em Educação) Faculdade de Educação, Universidade Estadual de Campinas (UNICAMP), Campinas, SP, 2002. Disponível em: http://repositorio.unicamp.br/handle/REPOSIP/253667. Acesso em: 2 jul. 2020. 
GUÉRIOS, E. Contribuiçóes do pensamento complexo para a formação de professores em uma perspectiva transdisciplinar. In: SÁ, Ricardo Antunes de; BEHRENS, Marilda. Aparecida (org.). Teoria da Complexidade: contribuiçôes epistemológicas e metodológicas para uma pedagogia complexa. Curitiba: Appris. 2019, p. 223-236.

MORAES, M. C.. Saberes para uma Cidadania Planetária. Homenagem a Edgar Morin. Rio de Janeiro: Wak Editora, 2019.

MORIN, E. Ciência com consciência. Rio de Janeiro: Bertrand Brasil, 1996.

MORIN, Edgar. Os Sete Saberes necessários à Educação do Futuro. 4 ed. São Paulo: Cortez. 2001.

MONTAGNINI, M. L; SUANNO, M. S. R. Formação pedagógica de professores universitários: ressignificação da atuação docente. In: LIBANEO. J.C; SUANNO, M. S. R; SUANNO, M. S. R (Org.). Didática e Escola em uma sociedade complexa. Goiânia, GO: CEPED, 2011 (a), p.193-226.

RIBEIRO, O. C.; MORAES, M. C. Criatividade em uma perspectiva transdisciplinar. Rompendo crenças, mitos e concepçôes. Brasília: UNESCO, 2014.

SOUZA, C .C. Z. O ensino da matemática financeira na escola numa perspectiva de educação para vida. 2016. Dissertação. (Mestrado em Educação). Universidade Federal do Paraná, Curitiba, PR, 2016.

SUANNO, M. S. R Formação Docente e Didática Transdisciplinar: aventura humana pela aventura do conhecimento. In: LIBANEO, J.C.; SUANNO, M. S. R.; LIMONTA, S.V. (Org). Concepçôes e práticas de ensino num mundo em mudança: diferentes olhares para a didática. Goiânia: CEPED/ Editora da PUC Goiás. 2011 (b), p. 195-206.

Recebido em: 28 ago. 2020

Aceito em: 01 dez. 2020 